\title{
Review
}

\section{Electrocatalytic Phenomena in Gas Phase Reactions in Solid Electrolyte Electrochemical Cells}

\author{
P.J. GELLINGS*, H.J.A. KOOPMANS and A.J. BURGGRAAF \\ Laboratory of Inorganic Chemistry, Materials Science and Catalysis, Department of Chemical \\ Technology, University of Twente, P.O. Box 217, 7500 AE Enschede (The Netherlands)
}

(Received 16 September 1987, accepted 11 January 1988)

\begin{abstract}
The recent literature on electrocatalysis and electrocatalytic phenomena occurring in gas phase reactions on solid, oxygen conducting electrolytes is reviewed. In this field there are a number of different subjects which are treated separately. These are: the use of electrochemical methods to study catalytic phenomena, electrocatalysis proper, the transfer of oxygen at the electrodes or electrolyte, and the (electro) catalytic properties of mixed, electronic and ionic, conducting materials.
\end{abstract}

\section{INTRODUCTION}

In this paper a survey is given of the recent literature on electrocatalytic phenomena in gas phase reactions using electrochemical cells with solid electrolytes. Although these can occur with any solid electrolyte this review is limited to a consideration of oxygen conducting electrolytes only.

The papers reviewed fall into four main categories:

(i) Those in which electrochemical methods are used to study catalytic phenomena occurring on the electrodes or electrolyte of the electrochemical cell considered.

(ii) Those in which the purpose is to influence a reaction by electrochemical means, i.e. those concerned with electrocatalysis proper.

(iii) Those in which oxygen transfer at the electrodes and/or the electrolyte is the main subject.

(iv) Those in which the (electro) catalytic properties of special, usually oxidic, materials with mixed conduction are studied.

It is not the purpose of this review to treat the whole subject area of solid state electrochemistry, a general review being available in the literature [1]. The discussion in this paper is limited to those papers in which (electro)catalytic phenomena are explicitly considered. 


\section{DEFINITIONS}

When talking about electrocatalysis there are several ways of increasing reaction rates by electrochemical means which have to be distinguished though not all of them are of a catalytic nature.

The first of these is based on Nernst's equation and is illustrated in Fig. 1. For this simple case the Nernst equation is:

$E=0.047 \log \left[\left(p_{\mathrm{O}_{2}}\right)_{1} /\left(p_{\mathrm{O}_{2}}\right)_{2}\right]$ at $873 \mathrm{~K}$

When a reaction occurring in the gas phase has a positive order in oxygen its rate will be enhanced at the anode upon applying a potential difference because this increases the oxygen activity.

When $E=-0.1 \mathrm{~V}$ eqn. (1) gives

$\left(p_{\mathrm{O}_{2}}\right)_{1} /\left(p_{\mathrm{O}_{2}}\right)_{2}=8.4$

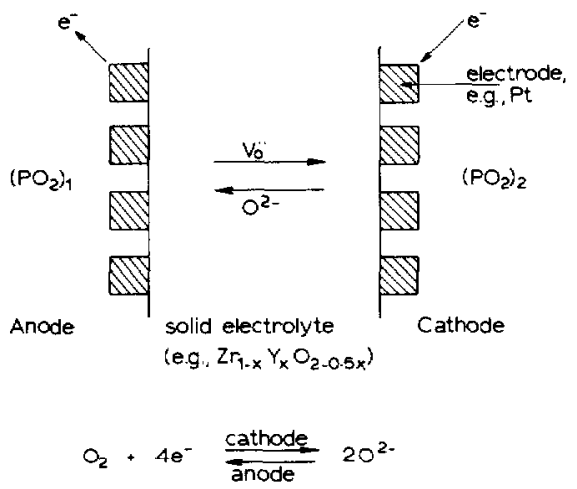

Fig. 1. Schematic representation of simple electrochemical cell with solid electrolyte.

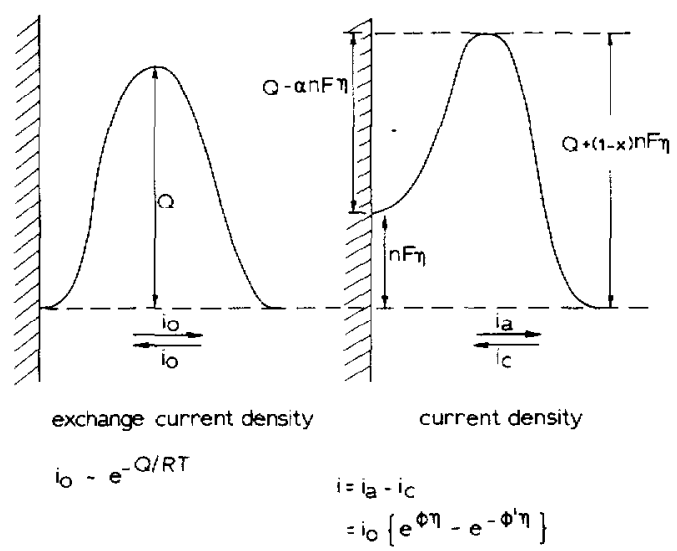

Fig. 2. Schematic potential energy diagrams for electrochemical reaction. 
while when $\mathrm{E}=-1.0 \mathrm{~V}$ we have:

$\left(p_{O_{2}}\right)_{1} /\left(p_{O_{2}}\right)_{2}=1.74 \cdot 10^{9}$

One important advantage of this possibility is that the oxygen activity can be increased without the need to add molecular oxygen to the reactants.

The second possibility is based upon the fact that the rate of any electrochemical reaction is changed by applying a potential difference. The resulting current density can often be approximated by an equation of the Butler-Volmer type (unless there is complete concentration polarization):

$\mathrm{i}=\mathrm{i}_{0}\left[\exp (\phi \eta)-\exp \left(-\phi^{\prime} \eta\right)\right]$

as indicated in Fig. 2. This implies that for a small value of the activation energy $Q$, the exchange current density $i_{0}$ is large and a small overvoltage is sufficient to give a large net current. The reverse applies for large $Q$. In this equation the exchange current density is influenced by the activation energy $Q$ and one might speak about catalysis proper when a mechanism is found to decrease this, e.g. by choosing another type of electrode material. This of course leads to a direct connection between catalytic and electrocatalytic properties and corresponds to the usual definition of electrocatalysis as the influence of the electrode material on the rate of an electrochemical reaction under otherwise constant conditions.

A third way in which an increase in reaction rate can occur is when the application of a potential difference causes the creation of new, active species at the surface of an electrode. This also leads to a catalytic effect. An example is given in the work by Goffe and Mason [2] on the electrolytic oxidation of hydrocarbons.

In the cases presented so far the rate of the reaction is observed to be proportional to the current through the electrochemical cell and we have what is usually called a Faradaic process.

A fourth way in which an increase in reaction rate can be achieved is via the increase in rate of a gas phase reaction which takes place at the surface of an electrode by the application of a potential difference. In this case it is not necessary that a measurable current flows: the only requirement is that the activation energy of the reaction under consideration is changed by the applied potential. This may be due either to an increase in activity of a surface species taking part in the reaction and/or to the start of a new reaction due to the activation of reaction sites which were previously inactive. This has, for example, been observed by Gür and Huggins [3] in the decomposition of nitric oxide.

In a number of cases the only purpose of (electro) catalysis is the increase in rate of a reaction. Examples are the oxidation of carbon monoxide to carbon dioxide, of sulphur dioxide to sulphur trioxide, or oxygen evolution or uptake 
TABLE 1

Gas composition for different conditions (concentrations given as mol fractions)

\begin{tabular}{lllc}
\hline Compound & Initial & $\begin{array}{l}\text { Complete* } \\
\text { equilibrium }\end{array}$ & $\begin{array}{l}\text { Partial }^{*} \\
\text { equilibrium }\end{array}$ \\
\hline Water & 0.1 & 0.05588 & 0.1 \\
Hydrogen & 0.2 & 0.2442 & 0.2 \\
Carbon monoxide & 0.21 & 0.166 & $(0.21)$ \\
Carbon dioxide & 0.21 & 0.254 & $(0.21)$ \\
Oxygen & $5.0 \cdot 10^{-6}$ & $1.4 \cdot 10^{-33}$ & $6.8 \cdot 10^{-33}$
\end{tabular}

*The figures in the third column have been obtained assuming complete equilibrium, those in the fourth column under the assumption that carbon monoxide and carbon dioxide are not in equilibrium with the other components.

in an oxygen pump, etc. But in many other cases it is even more important that the (electro) catalyst is selective, i.e. that it accelerates only one possible reaction. Typical examples are the oxidation of ammonia to nitric oxide for nitric acid manufacture, of propene to acrolein, the oxidative dehydrogenation of butene to butadiene, of ethylbenzene to styrene, etc. In comparing different systems or sets of conditions for certain reactions the selectivity is often used. However, in a number of cases this is somewhat misleading because if a high selectivity is only obtained at a (very) low conversion it is of no significance in practice. Therefore it is much better to make the comparison on the basis of total yield which is the product of conversion and selectivity.

In many cases it may be advantageous that a reaction can be made to proceed without molecular oxygen being present in the gas phase.

Not only in reactions applied to produce chemicals but also in other cases, for example in fuel cells and sensors, both catalytic activity and selectivity are of great importance. For example, it has been shown that platinum used as electrode material in oxygen sensors behaves catalytically, i.e. brings the components of a gas mixture at the gas-solid interface to thermodynamic equilibrium. The measured cell voltage then relates to the equilibrium $p_{\mathrm{O}_{2}}$ rather than to the actual, non-equilibrium value. In a mixture of the composition given in Table 1, for example, the output of an oxygen sensor, calculated with eqn. (1), is changed by $24 \mathrm{mV}$ depending on whether or not carbon monoxide and carbon dioxide are in equilibrium with the other components. Thus the output of a sensor, in an atmosphere containing oxidizable or reducible species, depends strongly on its selectivity.

\section{MEASURE FOR ELECI'ROCA'TALYTIC BEHAVIOUR}

In the literature there is not one single way which is used to characterize the behaviour of an electrocatalyst. One possibility is to compare the conversion 
of a reactant with the amount of oxygen transported through the electrolyte. However, in many cases several products may be formed and the total conversion is then not very informative.

The authors therefore, prefer to use a quantity similar to the selectivity as used in catalysis. However, the electrocatalytic selectivity factor $\xi$ proposed here is not calculated from the total formation of the product considered with respect to the reactant being converted, but from the increase in the rate of formation with respect to the oxygen flux through the electrolyte. If we consider the reaction:

$a \mathrm{~A}+m \mathrm{O}_{2} \rightarrow a \mathrm{AO}_{x}+b \mathrm{BO}_{y}$

the electrocatalytic selectivity factor is defined as:

$\xi=(2 \cdot m / a) \cdot D\left[r\left(\mathrm{AO}_{x}\right)\right] / j\left(\mathrm{O}^{2-}\right)$

Here $D\left[r\left(\mathrm{AO}_{x}\right)\right]$ is the increase in the rate of formation of the (desired) product $\mathrm{AO}_{x}$ caused by the flux $j\left(\mathrm{O}^{2-}\right)$ through the electrolyte (both expressed in the same unit, e.g. $\mathrm{mol} \cdot \mathrm{s}^{-1}$ ). The factor 2 arises because two oxygen ions are transported for each oxygen molecule which reacts and the factor $m / a$ because different amounts of oxygen are transported through the electrolyte for the formation of different products $\mathrm{AO}_{x}$. For example, in the reaction:

$\mathrm{CH}_{4}+\mathrm{O}_{2} \rightarrow \mathrm{CH}_{2} \mathrm{O}+\mathrm{H}_{2} \mathrm{O}$

one oxygen molecule is used for the production of one molecule of formaldehyde, but for the production of one molecule of methanol according to

$\mathrm{CH}_{4}+0.5 \mathrm{O}_{2} \rightarrow \mathrm{CH}_{3} \mathrm{OH}$

only half a molecule of $\mathrm{O}_{2}$ is used.

It is now possible to distinguish three regions for $\xi$ :

$0 \leqslant \xi<1$ : The reaction is not very selective. Performing the reaction in this way is only useful if the product cannot be obtained in another way. The extra oxygen pumped through the electrolyte is either evolved as molecular oxygen or is used for the formation of other products.

$\xi=1$ : If no extra oxygen is added to the mixture this is a favourable case. For the product considered the process is Faradaic.

$\xi>1$ : In principle this situation is not stable as more oxygen is extracted from the electrolyte than the amount pumped. In this case it is necessary to add oxygen to the reaction mixture. If $\xi$ remains $>1$ this means that the application of the electrical potential increases the number of active sites. In fact this is the most ideal situation.

The sum of the $\xi$-values, in case more than one product is formed simultaneously, is of course equal to the ratio of the total conversion of the reactant considered to the oxygen flux through the electrolyte. This quantity must be 1 for a purely Faradaic process but may be smaller or larger than 1 in other cases. 
Unfortunately the data presented in many papers are not complete enough to enable the calculation of the electrocatalytic selectivity factor $\xi$.

\section{ELECTROCHEMICAL STUDY OF CATALYTIC REACTIONS}

In this section we treat a number of examples where electrochemical methods have been applied to study catalytic reactions, mainly taking place on metallic catalysts which are simultaneously used as electrodes in a solid electrolyte electrochemical cell. In most cases the basic background to the treatment in these papers is the review by Wagner [4] on the principles of solid electrolyte potentiometry. This technique permits an in situ measurement of the thermodynamic activity of, e.g., oxygen adsorbed on metal film or mixed conducting catalysts.

\section{Measurement of oxygen activity}

The Nernst equation (1) is only valid in those cases where no chemical reactions other than oxygen transfer occur at the electrodes of a solid electrolyte cell. The general equation for the open circuit emf of such a cell is given by:

$E=(4 \cdot F) \cdot\left[\mu_{\mathrm{O}_{2}}\right.$ (catalyst $)-\mu_{\mathrm{O}_{2}}($ reference $\left.)\right]$

It is possible to define the oxygen activity $a_{O}$ on the catalyst by means of the equation:

$\mu_{\mathrm{O}_{2}}$ (catalyst $)=\mu_{\mathrm{O}_{2}}^{0}(g)+R T \ln \left(a_{\mathrm{O}}^{2}\right)$

Therefore $a_{0}^{2}$ expresses the partial pressure of oxygen in the gas phase that would be in thermodynamic equilibrium with the oxygen atoms adsorbed on the catalyst surface, if such an equilibrium were established [4,5]. Thus, if equilibrium is established between gaseous oxygen in the reactor and oxygen on the catalyst, then:

$a_{\mathrm{O}}^{2}=p_{\mathrm{O}_{2}}$

\section{Methane oxidation}

An example of the use of electrochemical measurements in the study of catalytic reactions is the study of the oxidation of methane with metallic silver as catalyst by Seimanides and Stoukides [6]. They used the silver, acting as the catalyst, as one electrode in a solid electrolyte electrochemical cell so that they could measure its potential with respect to a reference electrode (platinum in air) thus obtaining the oxygen activity during the reaction. In this way they were able to demonstrate that the reaction occurs via an Eley-Rideal mecha- 
nism between adsorbed oxygen and methane from the gas phase and also to determine the steady state oxygen activity. In the whole range of temperatures and compositions only carbon dioxide and water were formed in measurable quantities.

Recently the same authors studied this reaction in the same way on palladium as catalyst [7]. On this catalyst a similar mechanism was observed, with only carbon dioxide and water as reaction products, and the potentiometric measurements suggested that in the rate-limiting step only a single oxygen atom was involved.

In neither case is the oxygen activity $a_{\mathrm{O}}=\left(p_{\mathrm{O}_{2}}\right)^{1 / 2}$. However, the deviation from equilibrium between adsorbed and gaseous cxygen is much smaller than in the case of ethylene or hydrogen oxidation to be discussed later. This is clearly related to the much lower rates of methane oxidation.

\section{Sulphur dioxide oxidation}

Vayenas and Saltsburg [8] studied the oxidation of sulphur dioxide on noble metals by means of an electrochemical method with yttrium stabilized zirconia as electrolyte. Strictly speaking this is not an electrocatalytic study as the cell was used only on open circuit to measure emf values. The main conclusion of this work is that at low temperatures the desorption of sulphur trioxide and at high temperatures the adsorption of oxygen is the rate limiting step. Only at high temperatures and very low $p\left(\mathrm{SO}_{2}\right)$ is the surface reaction between sulphur dioxide and oxygen rate limiting. Furthermore the reason for the weakly catalytic or noncatalytic properties of gold and silver are not due to a qualitative difference with platinum but only to a quantitative difference in binding strength of product sulphur trioxide to the metal surface.

Mari et al. [9] also studied this reaction, using applied currents. An important conclusion from their work is that the electrochemically formed oxygen is in an active state making it possible to obtain sulphur trioxide yields much higher than predicted by thermodynamics under the given conditions, leading to much higher conversion efficiencies than with conventional catalytic reactors. Unfortunately, however, this was only done in very dilute gas mixtures: 93 ppm sulphur dioxide in helium, and it is doubtful whether this would be possible under more realistic circumstances of gas composition. The electrocatalytic selectivity factors were rather low: on platinum $\xi=0.09$, while on $\mathrm{V}_{2} \mathrm{O}_{5}$ $\xi$ lies between 0.15 and 0.35 , depending on the temperature.

\section{Carbon monoxide oxidation}

Okamoto et al. [10-15] extensively studied the oxidation of carbon monoxide on platinum using electrochemical measurements on cells with stabilized zirconia as the solid electrolyte. The emf measured in these cells is much larger 
than that calculated from the gas composition on the assumption that the cell in effect acts as an oxygen concentration cell. The authors propose, based on an original proposal by Fleming [16], that this is caused by the occurrence of a mixed potential due to the simultaneous occurrence of two coupled reactions:

$\mathrm{O}($ ads $)+2 \mathrm{e}^{-}=\mathrm{O}^{2-}$

$\mathrm{CO}($ ads $)+\mathrm{O}^{2-}=\mathrm{CO}_{2}+2 \mathrm{e}^{-}$

Even at low concentrations of carbon monoxide this leads to a large deviation in emf. This proposal was criticized by Vayenas [17] who pointed out that some of the proposed explanations were doubtful, in the first place because no product analyses were performed and in the second place because there was a confusion between "oxygen coverage" and "oxygen activity" in the paper by Okamoto et al. Although these authors [18] present arguments that for some of their measurements the lack of product analysis does not invalidate their conclusions this is certainly not true for all experiments. Furthermore their answer does not take away the doubts concerning the use of "oxygen coverage" vs. "oxygen activity" so that their conclusion about the occurrence of a mixed potential is by no means proven.

Furthermore there is another problem which arises out of some earlier work by Wen and Mason [19]. These authors observe that when oxygen is pumped through the electrolyte by means of an external emf there is hardly any reaction of carbon monoxide in contrast to what is observed with hydrogen. Unfortunately Okamoto et al. have not reported any measurements concerning the influence of the application of an external emf so that at the moment it is not possible to give an explanation for this effect.

\section{(Ep)oxidation of alkenes}

Stoukides and Vayenas [20] studied the epoxidation of ethylene on silver as catalyst. Measurement of the oxygen activity on the catalyst was observed to be described by

$p^{\frac{1}{\delta_{2}}} / a_{\mathrm{O}}=1+K \cdot p_{\mathrm{Et}} / p_{\mathrm{O}_{2}}$

with:

$K=3.4 \cdot 10^{-5} \cdot \exp (7800 / T)$

A Langmuir-Hinshelwood type mechanism with different adsorption sites for ethylene and oxygen explains the kinetics and the oxygen activity behaviour. Similarly these authors also studied the oxidation of ethylene oxide [21]. Here the measurement of the oxygen activity gave:

$p_{\mathrm{O}_{2}}^{\frac{1}{2}} / a_{\mathrm{O}}=1+K_{\mathrm{EtOx}} \cdot p_{\mathrm{EtOx}}$ 
with:

$K_{\mathrm{EtO}}=3.3 \cdot 10^{-5} \cdot \exp (10600 / T)$

In this case ethylene oxide is adsorbed as a dimer on different sites from oxygen.

The effect of electrochemical oxygen pumping was also studied by Stoukides and Vayenas [5] showing a significant increase in selectivity and yield for ethylene oxide formation although the maximum yield remained small: $2 \%$ without and $4.2 \%$ during oxygen pumping with a current of $50 \mu \mathrm{A}$ to the catalyst. On pumping oxygen from the catalyst the selectivity and the yield decreased, at $-50 \mu \mathrm{A}$ the yield dropped to $1.1 \%$. The increase in the rates of ethylene oxide and carbon dioxide formation exceeded the rate of oxygen pumping by two orders of magnitude ( $\xi=150$ to 300 for the epoxidation reaction) showing that the effect was not Faradaic but due to a change in either the nature or concentration of the active sites on the catalyst.

Vayenas et al. [22] studied the oxidation of ethylene in the same way but on platinum as the catalyst. Here it was found that:

$p_{\partial_{2}}^{\frac{1}{2}} / a_{\mathrm{O}}=1+K_{\mathrm{s}} \cdot p_{\mathrm{Et}} / p_{\mathrm{O}_{2}}^{\frac{1}{z_{2}}}$

,with $K_{\mathrm{s}}$ a function of temperature only. In a well-defined range of oxygen activities self-sustained oscillations occur which can be explained in terms of the stability of a surface platinum oxide.

In all these cases the oxygen activity is significantly smaller than that calculated for equilibrium which means that the surface reaction rate is comparable to or greater than the oxygen adsorption rate on these catalysts.

Another example is given by Stoukides and Vayenas [23,24] who studied the epoxidation of propene on porous silver electrodes. By pumping oxygen through a zirconia electrolyte to the active silver electrode both the rate and the selectivity of this reaction were increased (even though it remained very low). This was only possible at pumping currents which were up to two orders of magnitude smaller than the reaction rate itself, corresponding with very large electrocatalytic selectivity factors $\xi$ of $150-300$. The influence becomes constant upon increasing the pumping current. Thus in this case also there is a large change either in the number or in the type or properties of the active sites on the catalyst.

\section{Oxidation of benzene}

The oxidation of benzene was studied by Pizzini et al. [25,26] using $\mathrm{V}_{2} \mathrm{O}_{5}$ as the catalytically active electrode. The analysis given in these papers is not quite clear and a problem is that the quantities of two important products maleic anhydride and carbon monoxide - were not determined experimentally, but calculated from a material balance, so that definite conclusions about the selectivity are impossible. The electrocatalytic selectivity factor $\xi$ was approx- 
imately equal to 1 . The quantity of oxygen used corresponds both with oxidation to carbon monoxide and water and with that to maleic anhydride, carbon dioxide and water. Moreover the electrocatalytic experiments were performed at extremely low benzene concentrations ( $39 \mathrm{ppm}$ benzene in helium). In the light of these problems the claims of the authors concerning the value of this method of study seem somewhat exaggerated. It is shown that the method can be applied in measuring or removing trace amounts of benzene present in nonoxidizable gases.

\section{Oxidation of hydrogen}

Saranteas and Stoukides [27] studied the oxidation of hydrogen on a porous, polycrystalline nickel film supported on stabilized zirconia, again using solid electrolyte potentiometry to monitor the chemical potential of oxygen. It was observed that for large values of $p_{\mathrm{H}_{2}} / p_{\mathrm{O}_{2}}$ the oxygen activity can be ten orders of magnitude lower than predicted by assuming thermodynamic equilibrium between gaseous and adsorbed oxygen. On the catalyst surface a nickel oxide is formed, decreasing the activity of the catalyst. At high hydrogen:oxygen ratios the oxide is reduced and high rates are observed. The model in which the oxide is formed from adsorbed oxygen is in good agreement with the experimental results for the kinetics and potentiometric observations. This model does not explain the oscillatory behaviour which occurs under certain circumstances and further assumptions are necessary for this. Further experiments are also needed.

\section{ELECTROCATALYSIS}

In the following, a number of examples are discussed in which the purpose of the research was the influencing of a reaction by electrocatalytic means.

\section{Decomposition of nitric oxide}

Pancharatnam et al. [28] studied the catalytic decomposition of nitric oxide on platinum used as the cathode in a zirconia based electrochemical cell. The idea was that by pumping away the oxygen from the platinum surface its inhibiting effect on the decomposition could be prevented. They observed a very large increase in reaction rate, of about three orders of magnitude, which was ascribed to the formation of active sites on the zirconia, probably F-centres, so that the electrolyte itself became the site of the nitric oxide decomposition. The electrocatalytic selectivity factor based on oxygen evolution was $\xi=1$, but from the nitrogen evolution a value of $\xi$ of 2 to 20 , depending on the applied potential, no explanation being given for this difference. A further study of this reaction by Gür and Huggins [3] confirmed these results. In these experiments 
a nitric oxide-helium mixture was used and it is not known whether in the presence of other oxidizing gases, such as oxygen, which are usually also present in gases from which nitric oxide has to be removed a similar enhancement of the nitric oxide decomposition occurs. Before this method can be applied in practice, this has to be established.

As remarked by Steele [29] an alternative explanation for the enhanced reactivity is that under the strongly reducing circumstances intermetallic alloys may be formed by reaction between zirconia and the electrode material.

\section{Methane synthesis}

An interesting reaction is the formation of methane from carbon dioxide and hydrogen, studied by Gür and Huggins [30-32]. They used nickel and platinum electrodes at temperatures between 773 and $1363 \mathrm{~K}$ and concluded that in this reaction the first step is the reduction of carbon dioxide to carbon monoxide. This then dissociates on the surface after which the adsorbed carbon is hydrogenated to methane. The dissociation of carbon monoxide is facilitated by the application of the electric potential due to the strongly decreased effective oxygen pressure.

Nickel, which also shows methanation activity without the application of an electric potential, shows a much greater increase in activity than platinum which has no intrinsic methanation activity. Iron and cobalt also show increased methanation rates under dc biased conditions. The role of the metal is not yet clear as the authors propose that at the high voltages used the surface region of the zirconia becomes partially reduced and becomes mixed conducting. The large concentrations of electrons and oxygen vacancies enhance carbon monoxide adsorption and bond scission and thus explain the increased reaction rate under dc biased condition.

Whether this reaction can be used in practice is somewhat doubtful. In the first place the extremely reducing circumstances lead, as is also remarked by the authors, to decomposition of the solid electrolyte. Secondly only methane concentrations in the gas phase below $1 \%$ were obtained.

\section{Ammonia oxidation}

In the study by Farr and Vayenas [33,34] it was shown that oxidation of ammonia could be performed in a high temperature solid electrolyte fuel cell with a reasonable selectivity for the formation of nitric oxide of about 60 to $70 \%$. They concluded that higher selectivities will be possible by using a solid electrolyte with a smaller resistance, either by increasing the conductivity or by using a thinner electrolyte. The main reaction responsible for the low selectivity is the reaction of the nitric oxide formed in this reaction with the unconverted ammonia giving nitrogen. 
Sigal and Vayenas [35] used a new design for the electrochemical cell, with a thinner electrolyte and a decreased electrode surface area. This made it possible to obtain a much higher selectivity $(95 \%)$ combined with a reasonable power density $\left(0.6 \mathrm{~mW} / \mathrm{cm}^{2}\right)$. At the maximum power density of $4.9 \mathrm{~mW} / \mathrm{cm}^{2}$ the nitric oxide yield was only about $13 \%$. However, the maximum yield of nitric oxide, which could only be obtained at much lower power densities, was only about $35 \%$. Furthermore a very dilute gas mixture containing only $2 \%$ ammonia in helium was used, so that the conditions are still far removed from those encountered in practice.

\section{Oxidation of hydrocarbons}

Another case of this type is the oxidative dehydrogenation of ethylbenzene described by Michaels and Vayenas [36,37]. Although the selectivity was not high enough for practical purposes it was shown that by applying a potential difference it could be increased significantly when gas-phase hydrogen was added. In the absence of hydrogen the electrocatalytic selectivity factor $\xi$ was rather small $(0.05$ to 0.5 , depending on current density and ethylbenzene partial pressure) for the oxidative dehydrogenation to styrene and about 1 (Faradaic behaviour) for the total oxidation to carbon dioxide.

Ong et al. [38] studied the anodic overpotential behaviour of a number of fuel gases: hydrogen, carbon monoxide, methanol, ethanol and methane. From the observation that the activation energies are independent of whether platinum or gold is used as the electrode material these authors conclude that the reaction mainly takes place on the electrolyte. Furthermore they observe that anodic currents can be increased up to two orders of magnitude by using the electrolyte in a highly reduced ("blackened") state. This is ascribed to the formation of a large amount of F-centres, which act as the catalytically active sites. This is analogous to the decomposition of nitric oxide discussed above.

The electro-oxidation of hydrogen and hydrocarbon fuels in a solid electrolyte cell using gold or platinum as electrode material was studied by Goffe and Mason [2]. Because the differences in behaviour were observed to be rather small the authors propose that the main part of the oxidation occurs on the solid electrolyte acting as a catalyst. However, as these differences are certainly not negligible and the temperature at which the measurements were performed (973 K) was rather high, this conclusion seems somewhat premature. Furthermore the conclusions are only based on $i-\mathrm{V}$ measurements without analysis of the products formed during the reaction.

This work was recently extended by Nguyen et al. [39] and these authors present further evidence for the participation of the solid electrolyte surface in the electrochemical oxidation reaction. In the low overpotential range, charge transfer was rate limiting for both the cathodic and anodic reactions on gold as well on platinum, the current overpotential behaviour of these metals again 
being very similar. The electrolyte in the blackened, i.e. reduced, state is more active than the unblackened material, but the activation enthalpies do not deviate significantly. This is consistent with a reaction mechanism in which the major electrochemical steps occur on the electrolyte surface. The active sites are probably oxygen vacancies with electrons migrating along the electrolyte surface. Because the defect concentration increases on reduction (blackening) this explains the increase in activity.

\section{Oxidation and oxidative dehydrodimerization of propene}

Hayakawa et al. [ 401 studied the partial oxidation of propene on gold electrodes on yttria-stabilized zirconia. Without oxygen pumping no reaction was detected, even when oxygen was added to the propene-nitrogen-helium mixture. When oxygen was pumped through the solid electrolyte electrochemically, propene was oxidized to acrolein, carbon dioxide and carbon monoxide (selectivities at $1 \%$ conversion, based on propene 60,30 and $10 \%$ resp.). According to these authors no dioxygen was produced under the conditions stated. However, the conversion of propene, although being exactly proportional to the current through the solid electrolyte, was smaller than corresponded with the calculated value and led to an electrocatalytic selectivity factor $\xi=0.125$. For carbon monixide $\xi$ was 0.06 and for carbon dioxide 0.28 . The sum of the selectivity factors is thus $<1$ which means that more oxygen is being pumped through the electrolyte than used for the oxidation of propene. As the authors state that no dioxygen was evolved there remains an unexplained discrepancy.

It is shown by this work that, although gold itself is not able to catalyze the oxidation of propene by gaseous oxygen, the active oxygen species generated electrochemically can do so. Unfortunately the authors give no indication what happens to the selectivity at larger propene conversions.

In a later paper [41] these authors investigated the oxidation of propene on $\mathrm{MoO}_{3}-\mathrm{Bi}_{2} \mathrm{O}_{3}$ catalysts which were applied on top of an $\mathrm{YSZ}$ solid electrolyte. It was observed that the rate of acrylaldehyde formation on $\mathrm{MoO}_{3}$ was strongly increased by pumping oxygen through the electrolyte, while on $\mathrm{Bi}_{2} \mathrm{O}_{3}$ only oxygen evolution occurred. This supports the proposed mechanism for this reaction that oxygen insertion into the allylic intermediate occurs by a molybdenum species, while a bismuth species is involved in the incorporation of oxygen into the catalyst.

Di Cosimo et al. [42] studied the oxidative dehydrodimerization of propene at $600^{\circ} \mathrm{C}$ using a $\left(\mathrm{Bi}_{2} \mathrm{O}_{3}\right)_{0.85}\left(\mathrm{La}_{2} \mathrm{O}_{3}\right)_{0.15}$ disk as oxide-ion conducting catalyst separating the feed of $20 \%$ propene in helium on one side from air on the other side. The surface of the disk exposed to propene was reduced by the propene which was dehydrodimerized with a selectivity of $77 \%$ at $3.2 \%$ conversion (yield of hexadiene + benzene of $2.5 \%$ ) and was reoxidized by oxide ion conduction through the electrolyte. The driving force for the oxygen transport in this case 
was the oxygen pressure gradient over the solid electrolyte. The selectivity obtained in this way was significantly larger than in the case where oxygen was added to the propene-helium mixture where in the stationary state a selectivity of only 32 to $39 \%$ at $4.3 \%$ conversion was obtained (yield of hexadiene + benzene 1.4 to $1.7 \%$ ).

This result supports the proposal that lattice oxygen is predominantly involved in the selective oxidative dehydrodimerization of propene. It also demonstrates that oxide ion conductors based on bismuth sesquioxide can be used as catalyst in a reaction where reoxidation of the catalyst can occur by oxide ion conduction.

In order to reach higher yields by increasing the conversion it would be necessary to decrease the resistance of the cell, e.g. by using much thinner disks and/or a material with a higher conductivity.

\section{Methane coupling}

Oxidative coupling of methane over silver and $\mathrm{Ag} / \mathrm{Bi}_{2} \mathrm{O}_{3}$ catalysts was carried out by means of electrochemically pumped oxygen through yttria stabilized zirconia at $973 \mathrm{~K}$ by Otsuka et al. [43]. The $\mathrm{Ag} / \mathrm{Bi}_{2} \mathrm{O}_{3}$ catalyst was much more active and a greater part of the electrochemically pumped oxygen was used for the reaction. With silver alone about 90 to $98 \%$ of the oxygen was evolved as molecular oxygen $(\xi=0.08$ for carbon dioxide formation and $\xi=0.05$ for formation of ethane + ethene at low potential and 0.03 to 0 at high potential), with the $\mathrm{Ag} / \mathrm{Bi}_{2} \mathrm{O}_{3}$ catalyst 30 to $80 \%$ ( $\xi=0.5$ for carbon dioxide formation and $\xi=0.4$ for formation of ethane + ethene at low potential and 0.16 to 0 at high potential). With an externally applied electric potential both the methane conversion and the amount of $\mathrm{C}_{2}$ products formed are increased with respect to the case of a purely catalytic reaction. However, the total yield of $\mathrm{C}_{2}$ products remains practically the same!

Recently Seimanides and Stoukides [44] reported on the electrochemical modification of $\mathrm{Ag} / \mathrm{MgO}$ catalyst electrodes used for methane oxidation. $\mathrm{Ox}$ ygen pumping to the catalyst caused a decrease in ethene and an increase in carbon dioxide formation. Oxygen pumping from the catalyst gave increased formation of carbon monoxide and carbon dioxide. In both cases the ethane formation remained practically constant. Unfortunately no results for ethene formation were given for the case that oxygen was pumped from the catalyst. The sum of the values of $\xi$ was about 0.7 so that the total reaction is not completely Faradaic.

\section{Steam reforming and water-gas shift reaction}

Otsuka et al. [45] studied the production of hydrogen from water at the cathode of a solid electrolyte cell with stabilized zirconia as the electrolyte. At 
the anode hydrogen, methane, ethene and carbon monoxide are simultaneously oxidized. With carbon monoxide the total cell reaction is in effect the water-gas shift reaction, with the hydrocarbons it is steam reforming. The electrode material with the best electrocatalytic activity was silver. Applying an external potential gave an exponential increase in reaction rate. The measurement of the influence of gaseous concentration indicates that the anodic reaction is rate limiting. Although this method can be used in principle to produce pure hydrogen it is, as the authors also remark, still far removed from practical application. The production rate is still much too low and the measurements have only been performed at a water concentration of $2.7 \%$ in helium.

\section{OXYGEN TRANSFER}

Polarization phenomena of cathodic and anodic reaction of oxygen at platinum electrodes with doped $\mathrm{CeO}_{2}$ as electrolyte were investigated by Wang and Nowick [46]. At high $p_{\mathrm{O}_{2}}$ the $i-\eta$ curves show Butler-Volmer behaviour corresponding to a charge transfer mechanism. The oxygen for the charge transfer process is proposed to be supplied through atomically adsorbed oxygen on the platinum electrode. At low $p_{\mathrm{O}_{2}}$ limiting current behaviour is observed for the cathodic polarization, which is characteristic for diffusion polarization. When the cathodic polarization is studied in the current range above the cathodic limiting current reduction of the electrolyte occurs [47]. In this region the behaviour can best be described by the Wagner polarization cell theory [48] even though ionic blocking by the electrode is incomplete. The values obtained in this way for the electronic transference numbers for various electrolyte compositions and temperatures agree well with those obtained by other methods. In the process occurring during decay measurements primary diffusion of electrons from cathode to anode constitutes the first stage. Secondary diffusion of electrons out of the region of the working electrodes causes reduction in the neighbourhood of the reference electrode. In a study by Wang and Nowick of polarization of platinum, gold and silver electrodes on doped ceria [49] these authors conclude that the polarization behaviour is consistent with a mechanism in which charge transfer takes place in a two-phase region between the electrode and the electrolyte. However, the rate is determined by interfacial diffusion of oxygen atoms along the electrode. When the diffusion limitation is very high the concentration of adsorbed oxygen atoms becomes so low that reduction of the electrolyte occurs. The electronic contribution in this case can again be treated in terms of the polarization cell theory of Wagner.

Using single point contact electrodes Isaacs and Olmer [50] compared a number of oxygen catalytic electrodes on a zirconia electrolyte. The specific currents at a single overpotential of $-100 \mathrm{mV}$ varied over more than three orders of magnitude, thus showing the large influence of catalytic effects. The most active was rhodium, the least active gold. Also very active were perovskite 
type oxides based on $\mathrm{LaFeO}_{3}$ and $\mathrm{LaCoO}_{3}$ whereas one based on $\mathrm{LaCrO}_{3}$ was much less active (indeed even less active than platinum). It was not certain, however, if this was really due to catalytic effects or to a larger surface area, or to both. The effect of surface contamination in a number of cases demonstrated that the rate determining process occurred at the electrode surface.

The importance of the contribution of the electrolyte surface to the oxygen transfer reaction was also demonstrated by Olmer et al. [51] and by Schouler [52]. This is shown for example by the influence of doping the surface with foreign cations able to change their valence state at a potential close to that of the reaction studied. In this way it was possible to obtain oxidation of carbon monoxide on $\mathrm{ThO}_{2(1-x)}\left(\mathrm{YO}_{1.5}\right)_{x}$ and reduction of water on cerium doped yttria stabilized zirconia. To obtain this effect the presence of oxygen vacancies and mobile electrons at the surface is necessary, which are the same requirements as those for "ordinary" catalytic activity in this type of oxidation reaction.

In a recent paper Schouler and Kleitz [53] present evidence that both in oxygen evolution and in water reduction the onset of electronic conductivity in the electrolyte surface enhances these reactions and is responsible for electrocatalysis. Transition from pure ionic to mixed surface conductivity causes a large decrease in overvoltage for these reactions. Both at the cathode and at the anode the formation of mobile electronic defects also leads to a spreading of the reaction zone around the three-phase contact lines, thus increasing the active surface area.

Verkerk et al. [54] and Verkerk and Burggraaf [55] studied oxygen transfer on substituted $\mathrm{ZrO}_{2}, \mathrm{Bi}_{2} \mathrm{O}_{3}$ and $\mathrm{CeO}_{2}$ electrolytes with platinum electrodes in the temperature region of $770-1050 \mathrm{~K}$ in nitrogen-oxygen mixtures in the $p_{O_{2}}$ range of 1 to $10^{-5}$ atm. $\left(10^{5}-1 \mathrm{~Pa}\right) . \mathrm{On} \mathrm{Bi}_{2} \mathrm{O}_{3}-\mathrm{Er}_{2} \mathrm{O}_{3}$ the electrode resistance was observed to be much smaller than on $\mathrm{ZrO}_{2}-\mathrm{Y}_{2} \mathrm{O}_{3}$ and on $\mathrm{CeO}_{2}-\mathrm{Gd}_{2} \mathrm{O}_{3}$. On zirconia- and ceria-based materials diffusion of atomic oxygen on the platinum electrode is the rate determining step in the electrode process. For the bismuth containing material, on the other hand, diffusion on the oxide surface is rate determining at high oxygen partial pressures. At low $p_{\mathrm{O}_{2}}$ another process, for which diffusion of an electronic species in the electrolyte is proposed, is dominant. One of these processes also contributes to the electrode reaction on substituted ceria at high $p_{\mathrm{O}_{2}}$, where a charge transfer reaction is dominant.

Measurement of oxygen exchange from ${ }^{18} \mathrm{O}$ penetration profiles has been compared with the oxygen fluxes measured electrochemically [56]. For zirconia-based electrolytes these fluxes exhibit large differences, showing the importance of platinum as electro-catalyst. For bismuth containing materials a good agreement was observed between the fluxes. This led to the conclusion, supporting that of Verkerk and coworkers $[54,55]$ that dissociative adsorption of oxygen predominantly occurs on the surface of the electrolyte, so that the metal electrode has a much smaller effect on the oxygen transfer.

Recently Nguyen et al. [57] also studied the mechanism of the electrocatal- 
ytic reduction of oxygen in a solid electrolyte flow reactor. An important step in this mechanism is, according to these authors, molecular adsorption and diffusion of oxygen on the surface of the solid electrolyte. The charge transfer is proposed to take place in the two-phase region between the solid electrolyte and the gold electrode. At low oxygen pressures axial gas phase diffusion must be taken into account. At high oxygen pressures both charge transfer and surface diffusion are rate determining in the overall electrode reaction.

From the above it is clear that agreement on the reaction mechanism of the oxygen electrode has not yet been reached. Of course it may well be that the mechanism is not the same in different systems and/or under different circumstances. One common aspect is that in many cases it is now supposed that the electrolyte surface plays an important role in different systems and that the behaviour is certainly not determined only by the electrode metal.

\section{SENSOR APPLICATIONS}

From the very extensive literature on sensor applications only a few papers relevant for our purpose are reviewed here. A more extensive survey of the literature can be found in the review of Maskell and Steele [58].

Haaland [59] studied the poisoning of platinum electrodes used in oxygen sensors by lead and sulphur compounds and the use of gold or silver for this purpose. Because platinum behaves catalytically the oxygen content in nonequilibrium gas mixtures containing combustible components can not be measured accurately. Platinum electrodes poisoned with lead produced the smallest perturbation of non-equilibrium mixtures containing methane, propene, carbon monoxide or hydrogen at temperatures above $500-550^{\circ} \mathrm{C}$. At lower temperatures even the lead-poisoned electrodes are catalytic.

Badwal and Ciacchi [60] studied the performance of oxygen sensors with a stabilized zirconia electrolyte and nonstoichiometric oxide electrodes of the composition (U,M) $\mathrm{O}_{2 \pm x}$ with $\mathrm{M}=\mathrm{Sc}, \mathrm{Y}, \mathrm{Dy}, \mathrm{Pr}$. Using these materials good sensor behaviour is found at temperatures down to $350^{\circ} \mathrm{C}$ whereas using platinum electrodes large deviations from Nernstian behaviour were observed even at $450^{\circ} \mathrm{C}$. Both the electrode resistance and the response times were much lower than for platinum and the electrodes were much less sensitive to variations in the flow-rates of the gases. Because the conductivity of these materials is lower than for the electrolyte the better performance is, according to these authors, due to the much smaller electrode resistance which plays a dominant role (see also the following section). In all cases $\mathrm{PtO}_{2}$ was added to the electrode material in order to improve the adherence. The influence of this addition (between 15 and $35 \mathrm{wt} . \%$ ) on the sensor behaviour was only minor. 
xxx Van Dijk et al. [61,62] studied the oxygen electrode reaction on mixed conducting oxide surface layers obtained by radio frequent sputtering of $\mathrm{Gd}_{2} \mathrm{Zr}_{2} \mathrm{O}_{7}$ ( $\mathrm{TGZO}$ ), $\mathrm{Tb}_{2} \mathrm{Zr}_{2} \mathrm{O}_{7+y}$ or $\mathrm{Ce}_{0.7} \mathrm{~Tb}_{0.4} \mathrm{O}_{2-y}$ on $\mathrm{Gd}_{2} \mathrm{Zr}_{2} \mathrm{O}_{7}$ as solid electrolyte. These sputtered layers improve the oxygen electrode reaction compared to a bare specimen, in particular for TGZO. High electrode capacitances were found, which are probably due to injection of electronic charges in the mixed conducting oxide layer. These high capacitances lead to long relaxation times for the electrode reaction, which implies long response times in sensor applications. The values found for the electrochemical parameters suggest that a diffusion process is rate controlling and surface diffusion along the solid electrolyte or the sputtered layer can explain the different results for the different materials.

In electrocatalysis for applications where solid electrolytes at high temperatures are applied one of the key problems is the transfer of oxygen through the surface. As discussed above the oxygen is adsorbed on the metal, e.g. platinum, used as electrode where it dissociated in atoms. These then have to migrate to the three phase boundary line; platinum-gas-solid electrolyte. There they are charged and can be taken up by the electrolyte. An important limiting factor in this case is the small part of the surface which is available for oxygen transfer, as shown in Fig. 3. Therefore it is of interest to try to use electrode materials which have both electronic and ionic conduction, i.e. mixed conductors.

Electrocatalytic effects are expected in various reactions because in nearly all proposed mechanisms a charge transfer occurs in the rate determining step. In this respect materials with the fluorite structure and with the related pyrochlore structure, which is shown in Fig. 4, are of special interest. This is the case for the latter in particular because in the pyrochlore lattice there are two types of oxygen ions with different binding energies. this may also be of importance for the selective properties. Another interesting aspect of these materials is that the ordering of cations and of oxygen vacancies can be influenced by heat treatment which may also be important for the catalytic properties.

A number of materials which have been or are being investigated are collected in Table 2. Bismuth containing materials are studied in particular because, as discussed above [54,55], bismuth increases the rate of oxygen exchange.

One of the problems in the application of these materials is that for them to be effective both their electronic and ionic conductivity must be sufficiently high. This is illustrated by the calculation in Fig. 5 . However, as indicated by Badwal and Ciacchi, the ability to exchange oxygen is much better and this seems to be more important than the bulk resistance [60]. This is not entirely consistent with the explanation given by these same authors, mentioned in the 

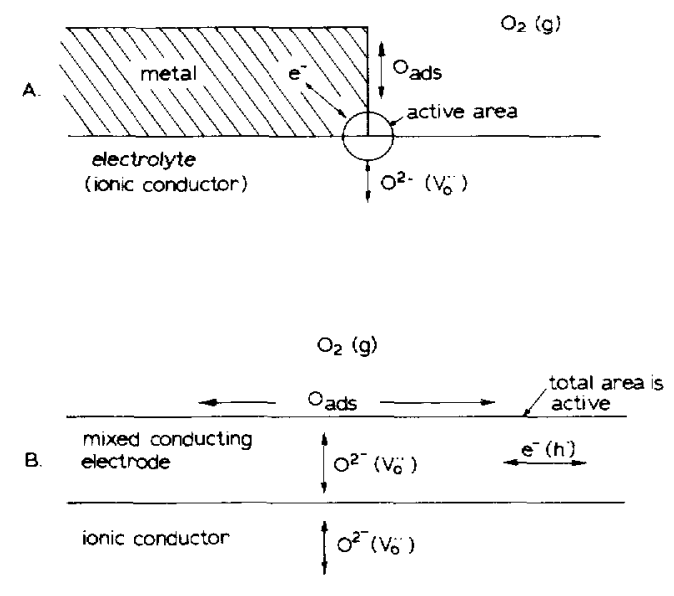

Fig. 3. Schematic representation of active areas with a metallic electrode and with a mixed conducting layer electrode.

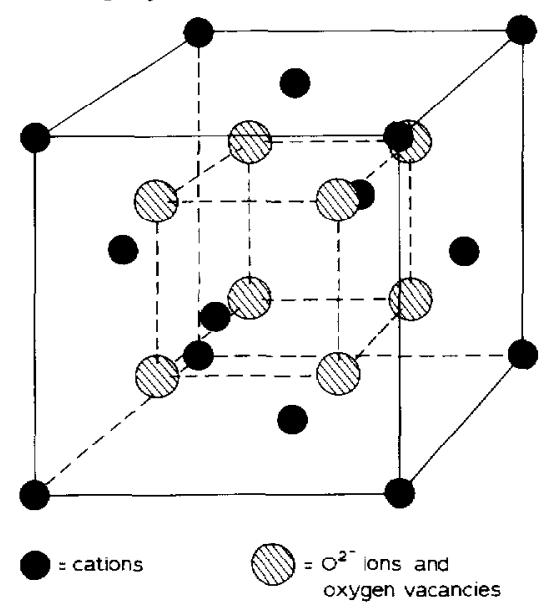

Fig. 4. Fluorite and pyrochlore structure. Fluorite (stabilized), e.g. $\mathrm{Zr}_{0.83} \mathrm{Y}_{0.17} \mathrm{O}_{1.915}$; cations oxygen vacancies are randomly distributed. Pyrochlore, e.g. $\mathrm{Gd}_{2} \mathrm{Zr}_{2} \mathrm{O}_{7}$ : cations and vacancies ordered.

previous section, that the properties of the electrode/electrolyte interface in particular dominate the behaviour.

For materials which do not show a sufficiently high intrinsic catalytic activity and/or selectivity a possible solution is to cover these with a monolayer of a material with appropriate catalytic properties [63].

Catalytic and electrical properties of some of these materials have recently been reported [64-67]. A problem which arises in the study of the electrocatalytic properties of these oxides is the very high activity of the common electrode material platinum as shown in Table 3. This makes it difficult to determine 
TABLE 2

Compounds under investigation

\begin{tabular}{ll}
$\left(\mathrm{Zr}_{1-x} \mathrm{Y}_{x}\right) \mathrm{O}_{2-0.5 x}$ & \\
$\mathrm{Nd}_{2}\left(\mathrm{Zr}_{1-x} \mathrm{Ce}_{x}\right) \mathrm{O}_{7}$, & \\
$\mathrm{Ln}_{2} \mathrm{Ti}_{2} \mathrm{O}_{7}$ & $\mathrm{Ln}=\mathrm{Y}, \mathrm{Eu}, \mathrm{Er}, \mathrm{Tb}$ \\
$\mathrm{M}_{x} \mathrm{Bi}_{1-x} \mathrm{Ti}_{2} \mathrm{O}_{7}$ & $\mathrm{M}=\mathrm{Y}, \mathrm{Tb}$ \\
$\mathrm{M}_{2} \mathrm{Sn}_{2} \mathrm{O}_{7}$ & $\mathrm{M}=\mathrm{Bi}, \mathrm{Tb}$ \\
$\left(\mathrm{Bi}_{1-x} \mathrm{Er}_{x}\right) \mathrm{O}_{3}$ & \\
$\left(\mathrm{Ce}_{1-x} \mathrm{Gd}_{x}\right) \mathrm{O}_{2-0.5 x}$ & \\
\hline
\end{tabular}

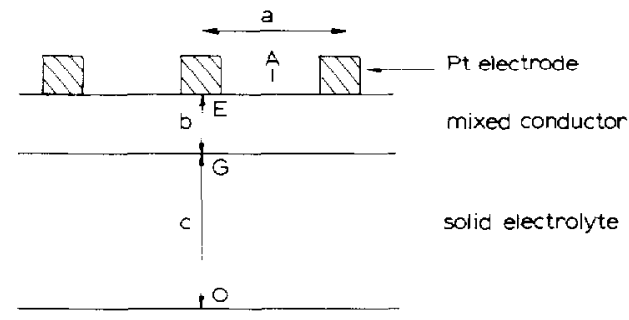

Fig. 5. Resistances in the application of layer electrodes. Typical values: $a=1 \mu \mathrm{m}, b=0.1 \mu \mathrm{m}$, $c=1000 \mu \mathrm{m} . \sigma_{\text {ionic }}$ (mixed conductor) $\simeq \sigma_{\text {innir: }}$ (solid electrolyte). The potential drop at A is negligible if $R_{E O}>100 \cdot R_{E A}$, this means: $1 /\left(\sigma_{\mathrm{i}}+\sigma_{\mathrm{e}}\right) \cdot b / a+1 / \sigma_{\mathrm{i}} \cdot c / a>100 \cdot 1 / \sigma_{\mathrm{e}} \cdot a / 2 b$ Thus: $\sigma_{\mathrm{e}}>\sigma_{\mathrm{i}} / 2$ so that the ionic transport number $t_{\mathrm{i}}$ must be below $2 / 3$. For $a=50 \mu \mathrm{m}$ (gold electrode) $t_{\mathrm{i}}$ must be below 0.001 .

\section{TABLE 3}

Catalytic reaction rates for carbon monoxide oxidation

\begin{tabular}{llc}
\hline & $\begin{array}{l}\text { Temperature } \\
(\mathrm{K})\end{array}$ & $\begin{array}{l}\text { Rate }(\mathrm{ml} \\
\left.\mathrm{CO}_{2}\right) \cdot \mathrm{min}^{-1} \cdot \mathrm{m}^{-2}\end{array}$ \\
\hline $\begin{array}{l}\text { Results of Yao [71] } \\
\quad \text { Platinum wire }\end{array}$ & 573 & 100 \\
Gold wire & 573 & 15 \\
$\mathrm{Co}_{3} \mathrm{O}_{4}$ & 473 & 25 \\
$\mathrm{LaCoO}_{3}$ & 473 & 2.3 \\
$\mathrm{LaMnO}_{3}$ & 573 & 2 \\
$\mathrm{Fe}_{2} \mathrm{O}_{3}$ & 573 & 0.4 \\
$\mathrm{NiO}$ & & 0.02 \\
Our results & & \\
$\mathrm{Nd}_{2}\left(\mathrm{Zr}_{0.9} \mathrm{Ce}_{0.1}\right) \mathrm{O}_{7}$ & 573 & 0.11 \\
$\mathrm{Bi}_{2} \mathrm{Sn}_{2} \mathrm{O}_{7}$ (fluorite) & 573 & 0.31 \\
ibid. (pyrochlore) & 573 & 2100 \\
ibid. & 473 & 0.14
\end{tabular}


unequivocally the catalytic properties of the mixed conductor because the platinum, used as electrode, may dominate the reaction.

Burggraaf et al. [68] have shown the importance of the type of oxidic material on charge transfer during electrochemical reaction. One conclusion is that for the materials studied introduction of $\mathbf{p}$-type electronic conductivity increases the electrode resistance and in particular the cathodic polarization. The electrochemical parameters can be interpreted on the basis of a mechanism consisting of a charge transfer process where both anodic and cathodic polarization are rate controlled by a diffusion process from an adsorption site to an electrochemical reaction site on the oxide surface. The importance of the chemical composition of oxidic interfaces as influenced by segregation and/or ion implantation has also been discussed by Burggraaf et al. [69].

\section{PREPARATION OF ELECTRODES}

As was shown by Ehrhardt et al. [70], the metal paints often used to obtain porous electrodes may contain contaminants which strongly influence the catalytic properties of the electrode material. A case in point is the presence of bismuth. If metal paints have to be used a special cleaning procedure must be applied in order to avoid wrong conclusions concerning the electrocatalytic behaviour.

\section{CONCLUDING REMARKS}

Looking back on the papers reviewed some general remarks can be made in conclusion.

(i) The use of electrochemical methods in studying catalytic reactions can give new and better insight into the phenomena occurring on the surface of a catalyst. This method is of course limited to conducting catalysts, mainly metals, but in special cases also to ionic conductors and/or semiconductors. Care has to be taken, however, that the conditions are well known. In particular it is important to distinguish cases where single electrode reactions are involved and cases where mixed potentials occur.

(ii) The practical use of gas phase electrocatalysis with solid electrolyte cells for the production of chemicals still seems to be extremely limited. Most examples given in the literature use conditions which are far removed from those used in practice. Moreover, even under these conditions the yields of the desired products are usually much too low to be of practical interest. Even in those cases where the reaction is accompanied by the production of electrical energy in a fuel cell the total benefit of the process is still too low.

(iii) The use of new types of electrolyte and electrode materials, especially those showing mixed conduction, may make it possible to obtain results which bring the practical application of gas-phase electrocatalysis much closer. 
(iv) Oxygen transfer is nearly always one of the reactions occurring in the cells considered. The rate determining step for this reaction often occurs at the cathode, the anodic overpotential in these cases being 0.01 to 0.05 of the total cell overvoltage. Thus for oxygen pumps the cathodic reaction may be the limiting factor for the rate of oxygen production.

(v) In chemical redox reactions the rate determining step may be the reaction at the anode, so that the anodic overpotential cannot be ignored in these cases.

(vi) In many cases it has been shown that not only the electrode metal but also the electrolyte plays an important role in the oxygen transfer reactions. This gives another way of influencing the processes occurring in high temperature electrochemical cells, sensors and reactors.

\section{ACKNOWLEDGEMENT}

The authors thank ir. B.C. Lippens Jr. for valuable discussions and for calculating a number of $\xi$-values.

\section{REFERENCES}

1 H. Rickert, Electrochemistry of Solids, An Introduction, Springer, Berlin, 1982.

2 R.A. Goffe and D.M. Mason, J. Appl. Electrochem., 11 (1981) 447.

3 T.M. Gür and R.A. Huggins, J. Electrochem. Soc., 126 (1979) 1068.

4 C. Wagner, Adv. Catal., 21 (1970) 323.

5 M. Stoukides and C.G. Vayenas, J. Catal,, 70 (1981) 137.

6 S. Seimanides and M. Stoukides, J. Catal., 88 (1984) 490.

7 S. Seimanides and M. Stoukides, J. Electrochem. Soc., 133 (1986) 1535.

8 C.G. Vayenas and H.M. Saltsburg, J. Catal., 57 (1979) 296.

9 C.M. Mari, A. Moltini and S. Pizzini, Electrochim. Acta, 24 (1979) 745.

10 H. Okamoto, H. Obayashi and T. Kudo, Solid State Ionics, 1 (1980) 319.

11 H. Okamoto, H. Obayashi and T. Kudo, Solid State Ionics, 3/4 (1981) 453.

12 H. Okamoto, G. Kawamura and T. Kudo, J. Catal., 82 (1983) 322.

13 H. Okamoto, G. Kawamura and T. Kudo, J. Catal., 82 (1983) 332.

14 H. Okamoto, G. Kawamura and T. Kudo, J. Catal., 86 (1984) 437.

15 H. Okamoto, G. Kawamura and T. Kudo, J. Catal., 87 (1984) 1.

16 W.J. Fleming, J. Electrochem. Soc., 124 (1977) 21.

17 C.G. Vayenas, J. Catal., 90 (1984) 371.

18 H. Okamoto, G. Kawamura and T. Kudo, J. Catal., 90 (1984) 374.

19 C.J. Wen and D.M. Mason, J. Appl. Electrochem., 8 (1978) 81.

20 M. Stoukides and C.G. Vayenas, J. Catal., 69 (1981) 18.

21 M. Stoukides and C.G. Vayenas, J. Catal., 64 (1980) 18.

22 C.G. Vayenas, B. Lee and J. Michaels, J. Catal., 66 (1980) 36.

23 M. Stoukides and C.G. Vayenas, J. Electrochem. Soc., 131 (1984) 839.

24 M. Stoukides and C.G. Vayenas, J. Catal., 82 (1983) 45. 
S. Pizzini, C.M. Mari and D.C. Hadjicostantis, in J. Wood, O. Lindqvist, C. Helgesson and N.-G. Vannerberg, (Eds.), "Reactivity of solids", Proc. 8th Int. Symposium on the Reactivity of Solids. Plenum Press, New York, 1977, p. 161.

S. Pizzini, C.M. Mari and L. Zanderighi, Gazz. Chim. Ital., 110 (1980) 389.

C. Saranteas and M. Stoukides, J. Catal., 93 (1985) 417.

S. Pancharatnam, K.J. Lim and D.M. Mason, J. Electrochem. Soc., 122 (1975) 869.

B.C.H. Steele, in: M. Kleitz and J. Dupuy (Eds.), Electrode Processes in Solid State Ionics, D. Reidel, Dordrecht/Boston, 1976, p. 367.

30 T.M. Gür and R.A. Huggins, Solid State Ionies, 5 (1981) 563.

31 T.M. Gür and R.A. Huggins, Science (Washington), 219 (1983) 967.

32 'T.M. Gür and R.A. Huggins, J. Catal., 102 (1986) 443.

R.D. Farr and C.G. Vayenas, J. Electrochem. Soc., 127 (1980) 1478.

C.G. Vayenas and R.D. Farr, Science (Washington), 208 (1980) 593.

C.T. Sigal and C.G. Vayenas, Solid State Ionics, 5 (1981) 567.

J.N. Michaels and C.G. Vayenas, J. Catal., 85 (1984) 477.

J.N. Michaels and C.G. Vayenas, J. Electrochem. Soc., 131 (1984) 2544.

B.G. Ong, C.C. Chiang and D.M. Mason, Solid State Ionics, 3/4 (1981) 447.

. Mason, J. Electrochem. Soc., 133 (1986) 1807

\section{Fukuda, J. Chem. Soc. Chem. Commun., (1986) 961.}

1 T. Hayakawa, T. Tsunoda, H. Orita, T. Kameyama, H. Takahashi, K. Fukuda and K. Takehira, J. Chem. Soc. Chem. Commun., (1987) 780.

42 R. Di Cosimo, J.D. Burrington and R.K. Grasselli, J. Catal., 102 (1986) 234.

43 K. Otsuka, S. Yokoyama and A. Morikawa, Chem. Lett., (1985) 319.

44 S. Seimanides and M. Stoukides, J. Electrochem. Soc., 133 (1986) 1535.

45 K. Otsuka, S. Yokoyama and A. Morikawa, Bull. Chem. Soc. Jpn., 57 (1984) 3286.

46 D.Y. Wang and A.S. Nowick, J. Electrochem. Soc., 126 (1979) 1155, 1166.

47 D.Y. Wang and A.S. Nowick, J. Electrochem. Soc., 127 (1980) 113.

48 C. Wagner in Proc. Seventh Meeting Int. Comm. Electrochem. Thermodyn. Kinetics (CITCE), Lindau, 1955, Butterworths, London, 1957, p. 361.

49 D.Y. Wang and A.S. Nowick, J. Electrochem. Soc., 128 (1981) 55.

50 H.S. Isaacs and L.J. Olmer, J. Electrochem. Soc., 129 (1982) 436.

51 L.J. Olmer, J.C. Viguie and E.J.L. Schouler, Solid State Ionics, 7 (1982) 23.

52 E.J.L. Schouler, Solid State Ionics, $9 / 10$ (1983) 945.

53 E.J.L. Schouler and M. Kleitz, J. Electrochem. Soc., 134 (1987) 1045.

54 M.J. Verkerk, M.W.J. Hammink and A.J. Burggraaf, J. Electrochem. Soc., 130 (1983) 70.

55 M.J. Verkerk and A.J. Burggraaf, J. Electrochem. Soc., 130 (1983) 78.

56 B.C.H. Steele, J.A. Kilner, P.F. Dennis, A.E. McHale, M. v. Hemert and A.J. Burggraaf, Solid State Ionics, $18 / 19$ (1986) 1038.

57 B.C. Nguyen, L.M. Rincon-Rubio and D.M. Mason, J. Electrochem. Soc., 133 (1986) 1860.

58 W.C. Maskell and B.C.H. Steele, J. Appl. Electrochem., 16 (1986) 475.

59 D.M. Haaland, J. Electrochem. Soc., 127 (1980) 796.

60 S.P.S. Badwal and F.T. Ciacchi, J. Appl. Electrochem., 16 (1986) 28.

61 M.P. van Dijk, K.J. de Vries and A.J. Burggraaf, Solid State Ionics, 21 (1986) 73.

62 M.P. van Dijk, K.J. de Vries and A.J. Burggraaf, Solid State Ionics, 21 (1986) 83.

63 J.G. van Ommen, K. Hoving, H. Bosch, A.J. van Hengstum and P.J. Gellings, Z. Physik. Chem., NF 134 (1983) 99.

64 M.P. van Dijk, J.H.H. ter Maat, G. Roelofs, H. Bosch, G.M.H. van de Velde, P.J. Gellings and A.J. Burggraaf, Recl. Trav. Chim. Pays Bas, 103 (1984) 38.

65 M.P. van Dijk, J.H.H. ter Maat, G. Roelofs, H. Bosch, G.M.H. van de Velde, P.J. Gellings and A.J. Burggraaf, Mat. Res. Bull., 19 (1984) 1149. 
66 J.H.H. ter Maat, M.P. van Dijk, G. Roelofs, H. Bosch, G.M.H. van de Velde, P.J. Gellings and A.J. Burggraaf, Mat. Res. Bull., 19 (1984) 1271.

67 S.J. Korf, H.J.A. Koopmans, B.C. Lippens Jr., A.J. Burggraaf and P.J. Gellings, J. Chem. Soc. Faraday Trans. 1, 83 (1987) 1485.

68 A.J. Burggraaf, M.P. van Dijk and K.J. de Vries, Solid State Ionics, 18/19 (1986) 807.

69 A.J. Burggraaf, M. van Hemert, D. Scholten and A.J.A. Winnubst, in P. Barret and L.-C. Dufour, (Eds.), Reactivity of Solids, Elsevier, Amsterdam, 1985, p. 797.

70 J.J. Ehrhardt, E. Häfele, H.-G. Lintz and A.F. Martins, Ber. Bunsenges. Phys. Chem., 89 (1985) 894.

71 Y. Yan, J. Catal., 39 (1975) 104. 